\title{
Gender as a Subject of Interdisciplinary Research
}

\author{
Natalia Malakhova \\ Department of Social Philosophy \\ Peoples' Friendship University of Russia \\ 6, Miklukho-Maklaya street \\ Moscow, Russia \\ natam_74@mail.ru
}

\begin{abstract}
The article emphasizes the interdisciplinary nature in the definition of such a thing as "gender". The author considers the main approaches to understanding "gender", presenting various reasons for defining the concept of "gender". The relevance of the study of biological and social factors in the nature of gender is shown. Formation of gender is considered as an integral part of human socialization.
\end{abstract}

Keywords-gender; sex; man; woman; gender role; gender socialization; gender differences; feminism; androgyny

\section{INTRODUCTION}

At present, there is no common understanding in science what 'gender' is. The problem is that gender is interpreted depending on the context in which it is studied sociocultural, psychological, political. Despite the fact that at the moment there is a sufficiently large number of interdisciplinary studies of gender, nevertheless there is no encyclopediac comprehension of this phenomenon in order to identify the criteria in the definition of the concept of 'gender'.

Gender studies (Zdravomyslova E.A., Temkina A.A., Voronina O.V., Lopata V.V., etc.) show that gender is present, constructed and reproduced in all social processes [1] [2] [3].

Discussion about the problem of the content of the concept of "gender", started back in the 1970s, continues to this day. As before, when studying gender, the question of the correlation of biological and social aspects in the nature of gender is topical.

\section{PSYCHOLOGICAL APPROACH}

What determines gender - nature or society? Kagan V.E. argues that "the dichotomy of the biological and social has outlived itself: environmental influences are a necessary condition for the realization of innate programs in the same way that innate programs are a necessary point of application of environmental influences" [4]. No one should forget that a human, whether a man or a woman, is a biosocial being and 'as an 'organism' a human is connected with nature, submits to natural necessity, and as a 'personality' is turned to social being with its specific laws" [5]. I.S. Kon notes that when studying a human - either a man or a woman - one should go from biology through psychology to the world of social phenomena [6]. And this view is shared by Ilyin E.P. [7]. Considering that the differences between a man and a woman are not explained solely by upbringing and socialization, the primary sources of these differences must be sought in the biological purpose of men and women. Biological characteristics of a person (sex, age, psychology) are a prerequisite for the social expression of sex - gender. According to many scientists, social life does not exist without natural. Biological (natural) is the eternal basis of various forms of life: individual, public and social [8]. This gives grounds to consider the differences between men and women in abilities, behavior, professional activity and family life as a comprehensive psycho-physiological problem that includes biological, psychological and social aspects. However, in addition to biological and social factors, there is one more point of view - the activity of a human himself/herself, aimed at creating gender. Here, the active role of human as a conscious subject of his/her own life is emphasized [9] [10].

It should be noted that in the national psychology, gender was interpreted from the standpoint of biological determinism and was considered as a socio-biological characteristic defining concepts such as 'man' and 'woman'. Since gender is a biological category, sexual differences are seen as a particular case of gender [11].

In the article What is Gender? the Russian researcher L.N Pushkarev notes that 'gender' is an ancient English word for "genus, tribe", originating from the Greek root 'genos' "birth, gender, origin", which means that the origins of the term 'gender' should be sought in antiquity. Reflections on the relationship between the concepts of the grammatical gender and the biological sex are found in the writings of ancient scientists and in medieval science. "Therefore, medieval sages said, the grammatical names of the masculine gender were attributed to such qualities as strength, power, activity, and so on (peculiar, as if, mainly, to men), and feminine nouns are passivity, weakness, dreaminess, sinfulness and so on (inherent, ostensibly, mainly, to women)" [12].

According to domestic psychologists, 'gender' can be a construct, both social and psychological. At the same time, the basis of gender is biological sex, but gender is transformed and consolidated in the process of gender socialization [13] [14]. 
S. Bern said, "Psychologists prefer to use the term 'gender', thereby emphasizing that many differences between men and women are created by culture, while the word 'sex' implies that all differences are a direct consequence of the biological sex" [15].

It is to emphasize not the natural, but the socio-cultural component of gender differences, to denote the totality of social and cultural norms that society prescribes to fulfill to people depending on their biological sex, the term 'gender' has been included in the scientific context. For the first time the term 'gender' was used by Robert Stoller in 1968 in a new, non-grammatical sense. He did this to distinguish the sociocultural characteristics of 'masculine' and 'feminine' 'masculinity' and 'femininity'.

\section{SOCIOLOGICAL APPROACH}

Another approach is sociological. Its representatives believe that since gender is not a natural given, but a social construct, it implies self-awareness and self-determination and includes such components as gender roles, gender norms, gender stereotypes and gender identity.

The theory of social construction of gender is based on the distinction between the biological sex and the social category of gender. Gender is "not the physical differences between a man and a woman, but the socially formed characteristics of masculinity and femininity", social expectations about the corresponding sex behavior [16].

The basis for understanding gender as a social construct was laid by P. Berger and T. Luckmann in his work The Social Construction of Reality. Treatise in the Sociology of Knowledge. According to the authors, social reality is both objective and subjective. This means that gender is created by people themselves every day, every minute, in a situation "here and now". This emphasizes the activity character of the subject: he not only assimilates and reproduces, but also creates gender relations and rules, and therefore, can destroy them. Therefore, gender can be viewed as an everyday world of interaction between the male and female, embodied in ideas, preferences, as a system characteristic of the social order, which is impossible to get rid of: it is constantly reproduced in the structures of consciousness, and in the structures of action and interaction [17].

In the sex-role model of T. Parsons, R. Bales, who develop the theory of gender socialization as a process of learning and internalizing cultural and normative standards, on the contrary, the personality appears as passive, perceiving and assimilating socially defined norms and standards of femininity and masculinity.

In R. Connell's structurally constructivist approach, gender relations are reproduced and changed as a result of the interaction of structural conditions and practices, in them representations about masculinity and femininity, gender ideologies, collective actions problematizing and changing the gender order are formed and maintained.

In the theory of the communicative systems of I. Hoffmann, the gender display is a mechanism for creating gender. Within this approach, gender is created every moment, here and now, in a specific situation of direct interpersonal interaction. Thus, the study of the living reality of human interaction, effective communication, actualization of public norms dictating to the communicator the necessity of observing the forms of behavior prescribed by the male and female roles is actualized. "Hoffmann argued that gender relations cannot be reduced to the implementation of gender roles, that gender cannot be changed, like dress, trousers or role in the play. It merged with the bodies of the interaction agents. The gender display as a representation of gender in interaction is so thin and complex that its performance cannot be reduced to replicas, suits, makeup and entourage" [18]. In case of violation of the 'gender display', a society can use to an individual who has not justified social expectations, both isolation and his/her compulsory treatment.

In the theory of social construction of gender, K. West and D. Zimmerman presented their understanding of gender. Gender is the achieved status (unlike the biological sex, which is a physiological given: "gender is a cultural correlate of sex, a consequence of biology and learning") ... Gender is a powerful ideological device that produces, reproduces and legitimizes elections and boundaries prescribed by the category of sex attribute" [19]. The authors of this approach believe that gender identity, formed by socio-psychological and cultural means, is formalized in a child of up to five years, and then the individual lives in harmony with it or tries to change it. In addition, they believe that gender is 'created' by the person himself/herself - a man or a woman in the process of social interaction. In their opinion, each individual constructs his/her own gender identity, and in the same way every individual instantly 'reads' the gender belonging of the other. The concepts of 'gender display' and 'gender role' reflect the behavioral aspects of expectations and interpretations related to the indispensable division into male and female.

The ethnomethodology of G. Garfinkel distinguishes between gender (the biological definition of a human as a man or a woman), the category of sex (the social definition of a human as a man or a woman) and gender (the normative characteristics of behavior that satisfy the social expectations of men and women).

Thus, from the point of view of the sociological approach, gender is understood as: a system of interpersonal interaction; as a sociocultural process of constructing gender differences by society, in behavior, emotional and psychological characteristics; as a social status that determines individual opportunities in professional activity, in education, access to power, family role and reproductive behavior.

\section{GENDER AND CULTURE}

An important component in the understanding of gender is a culture that acts as a determinative and regulating factor. Gender, contained in culture, to some extent affects the social relations that predetermine the development of society as a whole [20]. Representatives of the sociocultural approach emphasize that the social and cultural 
characteristics of gender are closely intertwined, and the notions of 'male' and 'female' depend on the historical period, social and cultural context, space and time. This allows you to take into account the alterability, variability, historicity, the difference between men and women, depending on age, marital status, attribution to a particular social class or ethnic group, etc. "Although a person is always a man or a woman, no one is ever just a man or only a woman. A human is young or old, healthy or poor, black or white and so on" [21].

In modern studies within the framework of the sociocultural approach, a term such as 'creative gender' appears. This term is used to substantiate the gender specificity of a creative person. The introduction of this term is conditioned by the fact that "the transformation of the cultural identity of the subject of creative activity into transitional epochs contributes to the formation of a special type of personality - androgynous, distinguished by a combination of features historically attributed to masculine and feminine sex roles" [22]. This means that the creative personality seeks to go beyond the scope of sociocultural expectations and overcome rigid requirements to gender roles.

\section{PHILOSOPHICAL APPROACH}

From the point of view of philosophy, gender can be considered on the basis of the following approaches: feminism and androgyny.

The feminist movement has contributed to the understanding of gender and gender. For example, the radical 'gender feminism', which relied on Marxist ideology, demanded the abolition of the sexes as classes, that is, required the abolition of the division of people into men and women. We all exist in the world not just as people, but always as a woman and a man. Such philosophers as S. Kierkegaard, F. Nietzsche believed that sex is a metaphysical necessity of human existence. In the case of the disappearance of 'sex differences', the person himself/herself and the culture created by him/her will die. Fromm also believed that male and female differences should survive, because every human being is an end in itself, which must have the freedom to develop his/her individuality.

The works of philosophers-feminists (A. Rich, R. Unger, G. Rubin) showed how the process of consolidating social roles and functions of the sexes is taking place and how society transforms the biological into the social. In the work of the psychologist R. Unger Toward a Redefinition of Sex and Gender, a clear definition of the concept of 'gender' for the first time has appeared, where she suggests using the word 'sex' when talking about special biological aspects of a person and using the term 'gender' when discussing social, cultural and psychological aspects, that is, norms, stereotypes, roles, character traits that are considered typical and desirable for women or men.

In the book Of Woman Born: Motherhood as Experience and Institution A. Rich shows that gender is a kind of system, interconnected with other power categories. According to A. Rich, along with such concepts as race, class, age, gender is a category that represents a hierarchy of social relations and roles between a man and a woman. In the studies of feminist anthropologists (M. Mid, M. Rosaldo, L. Lamphere, S. Ortner), the idea of differentiation of sex and gender was continued. They found that in different types of cultures there is a different understanding of male and female roles, as well as features and traits that characterize men and women.

In the studies of French feminists L. Irigaray, H. Cixous, J. Kristeva, another aspect of the understanding of gender is opened: cultural symbolic. In this approach, gender is interpreted as a cultural metaphor. As a cultural metaphor, gender serves as a symbol and is a culturally-forming factor. Gender can be imagined as a cultural sex mask [23].

Androgyny is mentioned in the writings of Plato. According to Plato, initially there were not two sexes, but three - male, female and androgynous. Plato assumed that the 'male' and 'female' half, of which the androgynes were composed, could be combined in different ways: not only the female with the male, but also the male with the male, and the female with the female. It is believed that the androgynous personality in the combination of male and female not only creates the necessary completeness and integrity, but also has the richest repertoire of sex-role behavior. A person demonstrating both masculine and feminine characteristics, reveals greater flexibility within sex-role behavior. The personal experience of harmony or disharmony of masculinity and femininity is a component of the 'androgynoprocess' and the moment of gender identification, the factors of which are biosocial and individual determinants, the individual's efforts, his/her selfidentification [24]. I.S. Kon believes that people who combine feminine and masculine qualities are more harmonious in their life, and, in contrast, the correspondence to sex-role stereotypes in society does not guarantee the psychological well-being of the individual.

Representatives of Russian religious philosophy believe that the ideal of the person is androgynous - a two-sexed being, a malefemale. The division into two sexes is the disintegration of the personality, its bifurcation, so the halves must be one flesh. V. Soloviev in his work The Meaning of Love says that "a true person in the fullness of his/her ideal personality cannot be only a man or only a woman but must be the highest unity of both" [25]. N. A. Berdyaev wrote, "human is not only a sexual being, but also a bisexual being that combines the male and female principles in different proportions ... Only the combination of the male anthropologically-personal principle with the female cosmiccollective one creates the fullness of human" [26].

\section{CONCLUSION}

Summing up, we can say that, depending on this or that approach, different grounds for determining gender are distinguished. If 'gender' as a term is a 'social sex', then as a concept 'gender' is a complex characteristic. Thus, from the point of view of the sociological approach, the meaning of the concept of 'gender' lies primarily in the idea of social construction of sex. The social sex is constructed by a 
society in which there is a system of norms, rules, etalons of behavior that prescribe the fulfillment of certain sexual roles. Hence a rigid series of ideas about what is 'male' and 'female' in a given society. In accordance with this approach, gender is a complex socio-cultural construct that points to differences in roles, behavior, mental and emotional characteristics between masculine and feminine, constructed by society.

From the point of view of psychologists in the definition of gender, it is important to take into account not only social, but also biological human functions (anatomical, physiological, hormonal, morphological). Therefore, in this approach, gender is a socio-biological characteristic defining the concepts of 'man' and 'woman'.

Studying the cultural aspect of gender, feminists define gender as a cultural metaphor and as a cultural sex mask.

Thus, summarizing different approaches, the following definition of gender can be given. Gender is a sociocultural characteristic of the biological sex, reflecting the behavioral, role, characterological features of men and women, changing depending on the specific cultural and historical environment.

Summarizing all of the above, we note that the very concept of "gender" has changed over and over again in content and volume, from the biological interpretation to modern interpretations based on a sociocultural basis and highlighting its peculiarity as a dynamic character. However, it is quite difficult to draw a line between biological givenness and its social component, since sex can actually exist only as a gender, that is, as a gender identity that a person acquires in the process of socialization from the birth.

\section{REFERENCES}

[1] E. A. Zdravomyslova, A.A. Temkina, Social Construction of Gender // Journal of Sociology. 1998, No. 3-4, pp. 171-182.

[2] O. A. Voronina, Sociocultural Determinants of the Development of Gender Theory in Russia and in the West // Social Sciences and Modernity, No. 4, 2000.

[3] V. V. Lopata, Features of Constituting Gender Identity in Modern Society: the socio-Philosophical Aspect. Thesis. Cand. Sc. Stavropol, 2013, $21 \mathrm{p}$.

[4] M. S. Kagan, Philosophy of Culture / M.S. Kagan. - SPb.: Publishing house Prosveshchenie, 1996. 309 p., p. 65.

[5] A. O. Bukhanovsky, A.S. Andreev, Structurally-Dynamic Hierarchy of a Person's Sex. - Rostov-na-Donu, 1993, 152 p., p. 10

[6] I. S. Kon, Sex Differences and Differentiation of Social Roles // The Correlation of Biological and Social in Man. M., 1975.

[7] E. P. Ilyin, Sex and Gender. SPb.: Piter, 2010, 688 p.

[8] L. E. Leukhina, Formation and Realization of Gender in the Everyday Life of Human Existence: Thesis. Cand. Sc. M., 2013.21 p.

[9] M. L. Bagramyants, Psychology of Giftedness: Theory, Experiment, Practice. Tutorial/ M.L. Bagramyants; Mosc. Econ.-Lingv. In-t. Dep-t of Gen. Psychology. Moscow, 2003.

[10] M. L. Ivleva, Philosophical Grounds for the Psychological Concept of Giftedness. Moscow, MSTU MAMI, 2011, 256 p.

[11] D. Myers, Social Psychology. SPb., 1997, p. 35.

[12] L. N. Pushkarev, What is Gender? (Terminological sketch)// A Woman in Russian Society, 1998, No. 4, p. 8.
[13] N. I. Lovtseva, Aspects of Gender Identity // Culture, Power, Identity - New Approaches in the Social Sciences/ Ed. E.R. YarskayaSmirnova. Saratov, 1999, p. 152.

[14] N. L. Pushkareva, Gender Studies: Birth, Formation, Methods and Perspectives in the System of Historical Sciences // Female. Gender. Culture. M., 1999, p. 21.

[15] S. Bern, Gender Psychology. SPb., 2001. 320 p., p. 26

[16] A. Hiddens, Sociology. M., 1999, p. 665.

[17] P. Berger, T. Luckmann, Social Construction of Reality, M., 1995.

[18] Gender Studies: Methodological Recommendations for Seminars and Independent Work / V.N. Kusurgashev; GOU VPO LNR Lugansk National Taras Shevchenko University. Lugansk: Kniga, 2017. 84 p., p. 41.

[19] K. West and D. Zimmermann, Creating Gender // Chrestomathy of Feminist Texts. SPb.: PH Dmitriy Bulanin, 2000, pp. 193-194.

[20] M. Kimmel, Gender Society / Translated from Engelish. M., 2006.

[21] Feminism: East. West. Russia / resp. ed. M.T. Stepanyants. M.: Nauka, 1993, p. 24

[22] N. A. Konopleva, Gender Foundations of Creative Activity and Creative Person in Culture. Thesis, Doctor of Cultural Studies. Vladivostok, 2012, 38 p., p. 20

[23] L. V. Shtyleva, Institutionalization of the Gender Approach / L.V Shtyleva // Higher Education in Russia. - 2004, No. 10. pp. 142-146.

[24] L.M. Bogatova, Phenomenology of Sex: Socio-Philosophical Discourse of the Problem. Thesis. Doctor of Philosophical Sciences: 09.00.11 / L.M. Bogatova; Tatar State Humanitarian and Pedagogical University. Kazan, 2009, 47 p., p. 4

[25] V.S. Soloviev, The Meaning of Love. K., 1991, p. 35.

[26] N.A. Berdyayev, The Destiny of Man. M., 1993, p. 6. 